Journal of Social Sciences (COES\&RJ-JSS)

ISSN (E): 2305-9249 ISSN (P): 2305-9494

Publisher: Centre of Excellence for Scientific \& Research Journalism, COES\&RJ LLC

Online Publication Date: $1^{\text {st }}$ July 2015

Online Issue: Volume 4, Number 3, July 2015

https://doi.org/10.25255/jss.2015.4.2.877.885

\title{
Intimate partner emotional abuse and post traumatic stress disorder among males
}

\author{
Seema Vinayak ${ }^{a}$, Najmeh Safariolyaei ${ }^{b}$, Pragun ${ }^{c}$ \\ ${ }^{a}$ Professor, Psychology Department, Panjab University, Chandigarh, India \\ ${ }^{\mathrm{b}} \mathrm{PhD}$ student, Psychology Department, Panjab University, Chandigarh, India \\ ${ }^{\mathrm{c}} \mathrm{BE}$ student, BITS, India
}

\begin{abstract}
:
Objectives: The emotional abuse of men by their partners has been acknowledged as an important form of partner abuse in domestic violence research. There is dearth of psychological research on alleged emotional abuse of males by their intimate partners. Methodology: The sample comprised of 150 heterosexual males (equal number of married and unmarried) in an intimate relationship aged 18-35 years. Emotional Abuse Questionnaire (EAQ; Gottman \& Gottman, 2009) and Impact of Event Scale (Weiss \& Marmar, 1997) were used. Results: Analysis of data showed that the intimate partner emotional abuse and PTSD were significantly correlated in both groups of males. The participants who were unmarried reported higher PTSD symptoms and emotional abuse than married men. Conclusion: Men who alleged to be the victims of intimate partner emotional abuse had higher symptoms of PTSD.
\end{abstract}

\section{Keywords:}

Intimate Partner Emotional Abuse, Male victims, PTSD.

\section{Citation:}

Vinayak, Seema; Safariolaei, Najmeh; Pragun (2015); Intimate partner emotional abuse and post traumatic stress disorder among males; Journal of Social Sciences (COES\&RJJSS), Vol. 4, No. 3, pp:877-885; https://doi.org/10.25255/jss.2015.4.2.877.885. 


\section{Introduction}

Psychological abuse, referred to as emotional abuse or mental abuse, is a form of intimate partner violence (IPV), characterized by a person subjecting or exposing another to behavior that may lead to psychological trauma, including anxiety, chronic depression, or post-traumatic stress disorder (Dutton, 1994; Thompson \& Kaplan, 1996; Maiuro \& O'Leary, 2004). Emotional abuse is like brain washing; in that, it systematically drains away at the victim's self-confidence, sense of self-worth, trust in their own perceptions, and self-concept. Whether it is done by constant berating and belittling, by intimidation, or under the guise of "guidance," "teaching," or "advice," the results are similar. Eventually, the recipient of the abuse loses all sense of self and remnants of personal value. Emotional abuse cuts to the core of a person, which creates scars that may be far deeper and more lasting than physical ones (Engel, 1992, p. 10).

A range of terms also has been used to describe the experiences of abuse in intimate relationships like domestic violence, domestic abuse, wife battering, wife beating, family violence/abuse and husband abusing (McHugh et al., 2005). Terms such as psychological abuse, psychological maltreatment, verbal abuse, emotional abuse or maltreatment, mental abuse, and psychological violence are commonly used interchangeably (Maiuro \& O'Leary, 2004).

Psychological abuse, a form of IPV, has two components (cognitive and emotional) and that the two do not necessarily overlap (O'Hagan, 1995). He defined cognitive abuse as aimed at undermining "the security of the victim's own logic and reasoning" whilst emotional abuse involves behavior "intended to undermine the victim's self-respect and sense of worth". There is no universally accepted definition of emotional abuse in like other forms of violence in relationships; emotional abuse is based on power and control (Outlaw, 2009, p. 246). The following are widely recognized as forms of emotional abuse: rejecting, degrading, terrorizing, isolating, corrupting, denying emotional responsiveness (Outlaw, 2009).

Since the beginning of research in abuse, the evidence of men sustaining abuse in romantic relationships has existed (Gelles, 1974). But typically women suffer more physical and psychological injuries than men who experience female perpetrated abuse (Archer, 2000; Hines \& Malley-Morrison, 2001). Male victims of domestic violence which includes emotional abuse as well have been seriously neglected in public policy, but they are not rare at all, they're just less likely to report it (NCFM, 2009). Researchers (Holtzworth-Munroe, 2005; Hines, 2007; \& Hines \& Malley-Morrison, 2011) have revealed the significance of IPV on men but there is lack of research which has studied specifically the intimate partner emotional abuse on men and possible consequences of such abuse. Black et al. (2011) found that approximately half of Americans reported experiencing lifetime emotional abuse by a partner. Psychological aggression was measured by combining questions based on both expressive aggression (e.g. name calling) and coercive control (e.g. isolation tactics or threats of harm). Psychological aggression by an intimate partner was reported by $48.4 \%$ of women and $48.8 \%$ of men. Consequently, emotional abuse appears to be the most common form of IPV. Karakurt and Silver (2013) suggested that men's overall risk of emotional abuse is increased while women's risk is decreased due to factors such as increased provision of resources for female victims and the role of law enforcement, along with women's empowerment through feminism, rates 
of both fatal and non-fatal IPV against women have declined in the past two decades (Rivara et al., 2002).

According to the Diagnostic and Statistical Manual (5th ed), PTSD is a psychiatric condition that follows the experience of a traumatic incident, and pays more attention to the behavioral symptoms that accompany PTSD and proposes four distinct diagnostic clusters. They are described as re-experiencing, avoidance, negative cognitions and mood, and arousal. Re-experiencing covers spontaneous memories of the traumatic event, recurrent dreams related to it, flashbacks or other intense or prolonged psychological distress. Avoidance refers to distressing memories, thoughts, feelings or external reminders of the event. Negative cognitions and mood represents myriad feelings, from a persistent and distorted sense of blame of self or others, to estrangement from others or markedly diminished interest in activities, to an inability to remember key aspects of the event. Finally, arousal which is marked by aggressive, reckless or self-destructive behavior, sleep disturbances, hypervigilance or related problems (American Psychiatric Association, 2013). Emotional abuse can also elicit posttraumatic stress disorder (PTSD) symptoms (Housekamp \& Foy, 1991; Kemp et al., 1991; Astin et al., 1993; Woods \& Isenberg, 2001).

Coker et al. (2005) explored PTSD symptoms in male and female survivors of abuse and found that the proportion of survivors meeting criteria (moderate to severe PTSD) were not different for men and women. Emotional abuse was just as strongly associated with PTSD as compared to physical abuse and women are more likely to perpetrate psychological than physical aggression toward male partners (Hines \& Saudino, 2003). Randle and Graham (2011) have demonstrated that men can experience significant psychological symptoms as a consequence of intimate partner abuse and experienced depression, psychological distress and PTSD. Though studies on IPV are found in literature but studies on intimate partner emotional abuse are lacking. The association between emotional abuse and negative health outcomes in men required more exploration in future to better understand this association.

This is important to explore intimate partner emotional abuse perpetrated against men, its consequences and to create public policies in order to prevent it. The goal of this study was to investigate intimate partner emotional abuse in men, which is a largely neglected area in social science research, and examine whether there is any relationship with posttraumatic stress disorder (PTSD).

\section{Method}

Participants and procedure:

Three hundred heterosexual males in the age range 18-35 years, and involved in an intimate relationship for at least 2 years were contacted. Out of these, 150 males with equal number of married and unmarried were randomly chosen. The data for the study was collected from Chandigarh, India. Men were asked basic demographic information such as age, income, education, occupation and also asked about current status of their relationship (Married, Unmarried but in intimate relationship for 2 years). The participants were from middle socio economic group and staying in nuclear family and they had minimum qualification as graduation. The exclusion included as sexual problems which require hospitalization or any psychological treatment, and other sexual orientation. 


\section{Measures}

Gottman Emotional Abuse Questionnaire (EAQ) -

This test was developed by Gottman and Gottman (2009). It consists of 25 items with two choices of true and false answers. Reliability and validity of test are satisfied.

Impact of Events Scale - Revised (IES-R)-

The IES-R was developed by Weiss and Marmar (1997) to reflect the DSM-IV criteria for post-traumatic stress disorder (PTSD). The original Impact of Events Scale (IES) predated the adoption of PTSD as a 'legitimate' diagnosis in the DSM-III of 1980 and measured two of the four DSM-IV criteria for PTSD.

\section{Statistical analysis}

Descriptive statics viz, mean and standard deviation and t test was applied. Correlations between intimate partner emotional abuse and post traumatic stress disorder (PTSD) were found.

\section{Results}

Correlations between an intimate partner emotional abuse (IPEA) and PTSD:

The investigation revealed that men who alleged intimate partner emotional abuse showed significant relationship with PTSD, $(\mathrm{r}=0.843, \mathrm{p} \leq 0.01)$. The results also indicated that when groups of married and unmarried were taken separately, there is significantly positive relationship between alleged intimate partner emotional abuse and PTSD in married men $(r=0.709, \mathrm{p} \leq 0.01)$ and unmarried men $(\mathrm{r}=0.866, \mathrm{p} \leq 0.01)$. Table 1 contains the mean, standard deviation and standard error mean of emotional abuse and PTSD for both married and unmarried and t-test indicates that the unmarried men reported higher alleged emotional abuse $(\mathrm{t}=7.614, \mathrm{p} \leq 0.01)$ and PTSD $(\mathrm{t}=8.128, \mathrm{p} \leq 0.01)$ as compared to married men.

Table 1.Mean, standard deviations and t-ratio values for married a n d unmarried on emotional abuse and PTSD

\begin{tabular}{|c|c|c|c|c|c|c|}
\hline & MS & $\mathrm{N}$ & Mean & Std. Deviation & $\begin{array}{l}\text { Std.Error } \\
\text { Mean }\end{array}$ & $\mathrm{t}$ - ratio \\
\hline Emotional Abuse & $\begin{array}{l}\text { Married } \\
\text { Unmarried }\end{array}$ & $\begin{array}{l}75 \\
75\end{array}$ & $\begin{array}{l}41.32 \\
57.67\end{array}$ & $\begin{array}{l}13.838 \\
12.418\end{array}$ & $\begin{array}{l}1.598 \\
1.434\end{array}$ & $7.614 *$ \\
\hline PTSD & $\begin{array}{l}\text { Married } \\
\text { Unmarried }\end{array}$ & $\begin{array}{l}75 \\
75\end{array}$ & $\begin{array}{l}44.15 \\
65.63\end{array}$ & $\begin{array}{l}13.422 \\
18.538\end{array}$ & $\begin{array}{l}1.550 \\
2.141\end{array}$ & $8.128 *$ \\
\hline
\end{tabular}

*Significant at $\mathrm{p}<0.01$ level

\section{Discussion}

The current study primarily aimed to investigate the associations between PTSD and intimate partner emotional abuse (IPEA), as a form of IPV victimization among men and consequently found the differences in married and unmarried men who alleged to be emotionally abused by their intimate partner. IPV is recognized as a serious problem, which affects the personal and familial well-being (Carmo et al., 2011). Straus (2005) reported that men are not considered traditional victims of intimate partner abuse, but between 2007 and 2009, males who denounced cases of IPV in Porto, compute for a 
relevant portion of all the victims of IPV. General awareness about this phenomena has increased over the years, therefore, it is expected that the number of victims who look for help may increase. Generally men do not report that they have been abused by their intimate partner, particularly because they are afraid of being an object of ridicule (Felson et al., 2005; Carmo et al., 2011). In a specific society, it is expected that men are not abused by women, but currently in western societies, where there is greater gender equality, the rate of male victims of intimate partner abuse has increased (Archer, 2006).

There have been various studies investigating emotional abuse against women, while research on emotional abuse against men is quite limited (Karakurt \& Silver, 2013). Results of the current study showed the significant correlation between alleged intimate partner abuse and PTSD in men.

Typically women suffer more physical and psychological injuries than men (Archer, 2000; Hines \& Malley-Morrison, 2001; \& Holtzworth-Munroe 2005). However, researchers have found the significance of intimate partner abuse on male victims (Hines \& MalleyMorrison, 2001; \& Hines, 2007). According to these studies (Dutton, 2005; Carney, 2007; \& Swan, et al., 2008) women are as capable as men to perpetrate abuse against their intimate partners and they do it more frequently.

Results of the present study are supported by a study which examined PTSD symptoms in male and female survivors of abuse and found that psychological abuse was strongly associated with PTSD as compare to physical IPV (Coker et al., 2005). In case of male victims, findings showed that women are more likely to perpetrate emotional than physical aggression toward male partners (Hines \& Saudino, 2003). In support of previous research (Dansky et al., 1999; Coker et al., 2005; Hines, 2007; \& Hines \& Douglas, 2011) present research found that for both samples (married and unmarried) men who alleged IPEA were significantly high on PTSD.

Results are consistent with the findings from the national intimate partner \& sexual violence survey (NISVS) by Black et al. (2011) who found that approximately half of Americans reported experiencing lifetime emotional abuse by a partner. Therefore emotional abuse appears to be the most common form of IPV.

Karakurt and Silver (2013) stated that "men's overall risk of emotional abuse may be increasing while women's risk may be decreasing. Due to factors such as increased provision of resources for female victims and the role of law enforcement, along with women's empowerment through feminism, rates of both fatal and non-fatal IPV against women have declined in the past two decades (Rivara et al., 2002). Researchers (Archer, 2000; \& Harned, 2001) reported similar rates of abuse between the genders, and they stated that there is a paucity of research examining emotional abuse of men, and there is some evidence that men are now experiencing increased rates of emotional abuse. The current study investigates men who alleged to be emotionally abused by their partners and the results can be interpreted through some theoretical paradigms.

The results can be partially understood through micro-resource conflict theory (Sprey, 1999), in terms of conflict resulting from changing gender roles. Men who perceived themselves to be emotionally abused report higher rates of emotional abuse as gender roles and the distribution of resources are changing (Karakurt \& Silver, 2013). Women are 
renegotiating roles and expectations because although they traditionally have been victims of patriarchal discrimination and inequality, in developed nations they increasingly have access to similar resources as men (Walker, 1999).

Consistent with past studies (Brinkerhoff \& Lupri, 1988; Stets \& Straus, 1989; Stets, 1991; Jackson, 1996; \& Anderson, 1997), results of present study showed that cohabiters generally have a higher risk of emotional abuse compared to married men and it might be because of availability of more social support and adjustment of marital status in married men. The current study found that unmarried men have an elevated risk of experiencing IPEA as compared to married men. However, the results showed that married men, who alleged IPEA, were significantly less likely to experience PTSD than those who were unmarried and in an intimate relationship. It might be due to better social support system and better coping strategies available within family and more responsibility attached to their relationship. Even today in India marriage is considered to be a sacred institution and people try to make more adjustments in married life. With social approvals, sometimes stressful conditions can be dealt with the help of other family members, thus reducing its important on health of the individual.

However, as Karakurt and Silver (2013) stated that "the effects of emotional abuse are just as detrimental as the effects of physical abuse". The law recognized physical and sexual abuse as crimes against the individual but not emotional abuse (Rivara et al., 2009). According to Black et al., (2011) emotional abuse is a penetrative form of relationship abuse. Therefore, it is important to further our knowledge on emotional abuse and its effects on human psychology and health.

\section{Conclusions}

From the results of this study, it can be concluded that men who alleged to be victims of intimate partner emotional abuse reported PTSD symptoms. Analysis showed that the association between alleged intimate partner emotional abuse and PTSD were significant and participants who were unmarried had higher PTSD symptoms and emotional abuse than married men. The results of this study and other works indicate that this may be the most fruitful way to provide treatment for men who have experienced IPEA and show PTSD symptoms.

\section{References}

American Psychiatric Association. (2013). Diagnostic and statistical manual of mental disorders (5th ed.). Washington, DC: Author.

Anderson, K. L. (1997). Gender, status, and domestic violence: An integration of feminist and family violence approaches. Journal of Marriage and the Family, 59(3), 655-669. Retrieved from https://irenemarshiajones.files.wordpress.com/2012/10/domestic-violencearticle-2.pdf

Archer, J. (2000). Sex differences in aggression between heterosexual partners: A metaanalytic review. Psychological Bulletin, 126, 651-680. Doi: 10.1037//00332909.126.5.651

Archer, J. (2006). Cross-cultural difference in physical aggression between partners: A social-role analysis. Personality and Social Review, 10(2), 133- 153. 
Astin B., Lawrence, K. J., \& Foy, D. W. (1993). Posttraumatic stress disorder among battered women: Risk and resiliency factors. Violence and Victims, 8(1): 17-28. Doi: 10.1177/1524838001002002001

Black, M. C., Basile, K. C., Breiding, M. J., Smith, S. G., Walters, M. L., Merrick, M. T., Chen, J., \& Stevens, M. R. (2011). The National Intimate Partner and Sexual Violence Survey (NISVS): 2010 Summary Report. Atlanta, GA: National Center for Injury Prevention and Control, Centers for Disease Control and Prevention.

Brinkerhoff, M. B., \& Lupri, E. (1988). Interspousal violence. Canadian Journal of Sociology, 4, 407-434. Doi: 10.1177/10778010022182128

Carmo, R., Grams, A., \& Magalhães, T. (2011). Men as victims of intimate partner violence. Journal of Forensic and Legal Medicine, 18$(\underline{8})$, 355-359. Doi: 10.1016/j.jflm.2011.07.006.

Carney, M., Buttell, F., \& Dutton, D. (2007). Women who perpetrate intimate partner violence: a review of the literature with recommendations for treatment. Aggress Violent Behavior, 12, 108-15. Doi:10.1016/j.avb.2006.05.002

Coker, A. L., Weston, R., Creson, D. L., Justice, B., \& Blakeney, P. (2005). PTSD symptoms among men and women survivors of intimate partner violence: The role of risk and protective factors. Violence and Victims, 20, 625-643. PMID: 16468442 [PubMed indexed for MEDLINE]

Dansky, B. S., Byrne, C. A., \& Brandy, K. T. (1999). Intimate violence and post-traumatic stress disorder among individuals with cocaine dependence. American Journal of Drug and Alcohol Abuse, 25, 257-268.

Dutton, D. G. (1994). Patriarchy and wife assault: The ecological fallacy. Violence and Victims, 9, 125-140. Retrieved from file:///C:/Users/Najmeh/Downloads/DUTTON.1994.-PATRIARCHY-AND-WIFE-ASSAULT-THE-ECOLOGICAL-

FALLACY.\%20(1).pdf

Dutton, D. G., Nicholas, T. L., \& Spidel, A. (2005). Female Perpetrators of Intimate Abuse. Women Who Perpetrate Relationship Violence: Moving Beyond Political Correctness. (pp1-31). The Haworth Press, Inc. Doi: 10.1300/J076v41n04_01

Engle, B. (1992). The Emotionally Abused Woman: Overcoming Destructive Patterns and Reclaiming Yourself. New York: Fawcett Columbine.

Felson, R. B., \& Paré, P. (2005). The reporting of domestic violence and sexual assault by nonstrangers to the police. Journal of Marriage and Family, 67, 597-610. Doi: 10.1111/j.1741-3737.2005.00156.x

Gelles, R. J. (1974). The violent home: A study of physical agression between husbands and wives. Beverly Hills, CA: Sage.

Gottman \& Gottman (2009). Gottman Emotional Abuse Questionnaire (EAQ). Distributed under license by The Gottman Institute, Inc.

Harned, M. S. (2001). Abused women or abused men? An examination of the context and outcomes of dating violence. Violence and Victims, 16(3), 269-85. PMID: 11437117 [PubMed - indexed for MEDLINE]

Hines, D. A. (2007). Post-traumatic stress symptoms among men who sustain partner violence: A multinational study of university students. Psychology of Men \& Masculinity, 8, 225-239. Doi: 10.1037/1524-9220.8.4.225

Hines, D. A., \& Douglas, E. M. (2011). Symptoms of posttraumatic stress disorder in men who sustain intimate partner violence: A study of helpseeking and community samples. Psychology of Men \& Masculinity, 12(2), 112-127. Doi:10.1037/a0022983. 
Hines, D. A., \& Malley-Morrison, K. (2001). Psychological effects of partner abuse against men: A neglected research area. Psychology of Men \& Masculinity, 2(2), 75-85. Doi:10.1037//15249220.2.2.75

Hines, D. A., \& Saudino, K. J. (2003). Gender differences in psychological, physical, and sexual aggression among college students using the Revised Conflict Tactic Scales. Violence and Victims, 18, 197-217. PMID: 12816404 [PubMed - indexed for MEDLINE] Holtzworth-Munroe, A. (2005). Male versus female intimate partner violence: Putting findings in context. Journal of Marriage and Family, 67, 1120- 1125. Doi: 10.1111/j.1741-3737.2005.00203.x

Housekamp, B. M., \& Foy, D. W. (1991). The assessment of posttraumatic stress disorder in battered women. Journal of Interpersonal Violence, 6, 367-375.

Jackson, N. A. (1996). Observational experiences of intrapersonal conflict and teenage victimization: A comparative study among spouses and cohabitors. Journal of Family Violence, 11(3), 191-203.

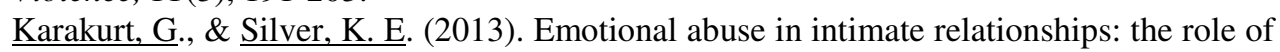
gender and age. Violence Victim, 28(5), 804-821. Retrieved from: http://www.ncbi.nlm.nih.gov/pmc/articles/PMC3876290/pdf/nihms419073.pdf

Kemp, A., Rawlings, E. I., \& Green, B. L. (1991). Post-traumatic stress disorder (PTSD) in battered women: A shelter sample. Journal of Traumatic Stress, 4, 137-148. Doi: 10.1002/jts.2490040111

Maiuro, R. D., \& O'Leary, K. D (2004). Psychological Abuse in Violent Domestic

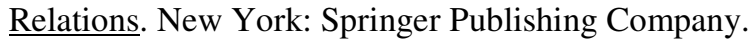

McHugh, M. C., Livingston, N. A., \& Ford, A. (2005). A postmodern approach to women's use of violence: Developing multiple and complex conceptualizations. Psychology of Women Quarterly, 29, 323-336. Doi: 10.1111/j.1471-6402.2005.00226.x

National Coalition For Men (NCFM, 2009). Domestic Violence. Retrieved from: http://ncfm.org/know-the-issues/mens-rights-issues/

O'Hagan , K. P. (1995). Emotional and psychological abuse: problems of definition. Child Abuse Neglect, 19(4), 449-61. PMID: 7606523 [PubMed - indexed for MEDLINE]

Outlaw, M. (2009). No one type of intimate partner abuse: Exploring physical and nonphysical abuse among intimate partners. Journal of Family Violence, 24(4), 263-272. Doi: 10.1007/s10896-009-9228-5

Randle, A. A., \& Graham, C. A. (2011). A review of the evidence on the effects of intimate partner violence on men. Psychology of Men and Masculinity, 12(2), 97-111. Doi: $10.1037 / \mathrm{a} 0021944$

Rivara, F. P., Anderson, M. L., Fishman, P., Reid, R. J., Bonomi, A. E., Carrell, D., \& Thompson, R. S.(2009). Age, period, and cohort effects on intimate partner violence. Violence and Victims, 24(5), 627-38. Doi: 10.1891/0886-6708.24.5.627

Sets, J. E. (1991). Cohabiting and marital aggression: The role of social isolation. Journal of Marriage and the Family, 53(3), 669-680. Retrieved from: http://www.jstor.org/stable/352742?seq=2\#page_scan_tab_contents

Sprey, J. (1999). Family dynamics: An essay on conflict and power. In M. B. Sussman, S. K. Steinmetz, \& G. Peterson (Eds.), Handbook of marriage and the family (2nd ed., pp. 667-685). New York: Plenum press.

Stets, J. E., \& Straus, M. A. (1989). The marriage license as a hitting license: A comparison of assaults in dating, cohabiting, and married couples. Journal of Family Violence, 4(2), 161-180. Doi: 10.1007/BF01006627 
Straus, M. A. (2005). Women's violence toward men is a serious social problem. In D. R. Loseke, R. J. Gelles, \& M. M, Cavanaugh (eds.), Current controversies on family violence (2nd eds., pp. 55-77). Newbury Park: Sage Publications.

Swan, S. C., Gambone, L. J., Caldwell, J. E., Sullivan, T. P., \& Snow, D. L. (2008). A review of research on women's use of violence with male intimate partners. Violence and Victims, 28, 301-14.

Thompson, A. E., \& Kaplan, C. A. (1996). Childhood emotional abuse. British Journal of Psychiatry. 168(2), 143-8. PMID 8837902

Walker, A. (1999). Gender and family relationships. In M. Sussman, S. K. Steinmetz, \& G. W. Peterson (eds.), Handbook of marriage and the family (2nd ed., pp. 439-474). New York: Plenum press.

Weiss,D. S., \& Marmar, C. R. (1997). The impact of event scale - revised. In J. P. Wilson, \& T. M. Keane (eds.), Assessing psychological trauma and PTSD, (399-411). New York: Guilford, Press.

Woods, S., \& Isenberg, M. A. (2001). Adaptation as a mediator of intimate abuse and traumatic stress in battered women. Nursing Science Quarterly, 14, 215-221. Doi: $10.1177 / 0886260504267882$ 